\title{
Posicionamentos da ANPEd sobre a reforma da educação superior em curso
}

\section{Introdução}

O Ministério da Educação (MEC) deverá encaminhar ao Congresso Nacional a Lei Orgânica da Educação Superior até o final de 2004. A valer as pretensões do ministério, a nova lei será ampla e deverá abranger tanto as instituições públicas, como regular a relação do MEC com as instituições privadas, redefinindo os rumos da educação superior brasileira.

Considerando a importância e gravidade desse momento para a educação superior brasileira, a Associação Nacional de Pós-graduação e Pesquisa em Educação (ANPEd) reafirma alguns pressupostos que, a seu ver, são indispensáveis a uma política de educação superior e que, ao longo de muitos anos, têm se constituído em objeto de estudo e análise de seus associados.

A ANPEd compreende que a educação, de modo geral e especificamente a de nível superior, deve ser objeto de atenção privilegiada do governo, da comunidade científica e da sociedade como um todo. Nessas circunstâncias, a ANPEd partilha do consenso de que esse debate não se contém nos limites restritos de prazos estabelecidos, mas, ao contrário, se obriga ao diálogo amplo e permanente.

Partindo da constatação de que o sistema de Educação Superior deva se constituir em novo marco político, legal, institucional e administrativo capaz de qualificar e orientar o conjunto da educação superior brasileira, advoga a necessidade de que tal sistema apresente uma regulação orgânica, articulada aos princípios que regerão a pós-graduação e a produção científica e tecnológica, guardando, ainda, íntima articulação com o Sistema Nacional de Educação, do qual a educação superior é parte constitutiva.

Defende também, em sentido contrário ao veiculado nas reuniões do Acordo Geral para o Comércio de Serviços (GATS) e da Organização Mundial do Comércio (OMC), que a educação deve ser entendida como bem público que requer rigoroso planejamento nacional, regido por alguns pressupostos.

\section{Da relação público-privado}

Compreende-se, inicialmente, que a educação superior é um direito de cidadania, cabendo ao Esta- 
do e ao fundo público estatal, em seus diferentes níveis, a responsabilidade pela criação, expansão e manutenção desse nível de ensino. Assim, defende-se que as políticas para a educação superior deverão ser sempre políticas públicas de Estado, que não transfiram a execução de suas atribuições constitucionais para o setor privado - como poderá ocorrer, por exemplo, caso se apliquem as regras das Parcerias Público-Privadas ${ }^{1}$ ao campo da educação superior e não se orientem por ações focais concretizadas em programas assistenciais.

Entende-se que tais políticas devam coibir a privatização indireta das instituições de ensino superior pública, privatização que pode ocorrer pela introdução de mecanismos de administração e gerenciamento empresariais, especialmente para a busca de recursos junto ao mercado, isso porque a formulação de contratos de pesquisa com empresas, venda de serviços e consultoria, entre outros procedimentos, abrem caminho para a transformação dos produtos da educação superior - em especial, os vinculados à educação a distância - em mercadorias, em bens privados. Sob esse entendimento, a ANPEd manifesta sua discordância em relação ao projeto de lei n ${ }^{\circ} 3.476 /$ 04, conhecido como Lei de Inovação Tecnológica, que tramita no Congresso Nacional, especialmente pelo fato de ele não estar sendo discutido articuladamente com a Reforma Universitária.

Em síntese, reafirma que a elaboração e a implementação da reforma devem ser fruto de uma política de Estado para o ensino, a pesquisa e a extensão no país, a fim de evitar a ocorrência de decisões vulneráveis ao jogo das circunstâncias de governos e grupos.

Referência ao projeto de lei $n^{\circ} 2.546 / 2003$, aprovado em 17 março de 2004, na Câmara dos Deputados, e em tramitação no Senado até a presente data. Nesta direção e pensando em uma perspectiva orgânica, causa preocupação o "Projeto Escola na Fábrica", cuja proposta de instalação de unidades de qualificação profissional no próprio ambiente de empresas, constitui-se em mais um exemplo da invasão da visão empresarial na educação.

\section{Financiamento da educação superior}

Primeiramente, é preciso que se considere que não há mágica possível para a necessária expansão da rede de educação superior, para a elevação de sua qualidade e manutenção de seu caráter público: maior investimento do Estado, para a rede pública de graduação e pós-graduação, constitui-se em condição básica. Em decorrência, discorda que a educação superior venha a ser tratada como coadjuvante dos programas de ajustes fiscais, submetida a cortes e contingenciamentos, tendo em vista o enxugamento da máquina do Estado, advogando para esse setor, dentre outros, maior centralidade nos planejamentos políticos estatais.

Considerando a atual situação das instituições de educação superior públicas, a ANPEd reafirma que nenhuma Reforma terá a eficácia que se pretende se não forem revertidos o reconhecido déficit de docentes e pesquisadores, bem como a degradação da infraestrutura das instituições de ensino superior. Sem resolver essas pendências, o desenvolvimento da pesquisa, o ensino e a extensão nessas instituições estarão irremediavelmente comprometidos. Investimentos efetivos fazem-se necessários, abrangendo equipamentos, instalações, redes e terminais de informática, bibliotecas físicas e virtuais, dentre outros, além da contratação de serviços para instalação, manutenção, operação, modificação e adaptação dessa infra-estrutura.

Considera importante lembrar que uma das tarefas prioritárias das universidades reside na formação de profissionais da educação e que, para tanto, faz-se necessária à valorização das faculdades e centros de educação como espaços de produção do conhecimento educacional e responsáveis pela formação desses profissionais. Assim, destaca a necessidade premente de valorização em termos administrativos, acadêmicos e financeiros das licenciaturas e dos cursos de pedagogia, a implementação de mudanças na articulação com a escola de educação básica, o incentivo à pesquisa $\mathrm{e}$ bolsas de iniciação científica, a garantia de acesso e permanência da juventude que opta pela profissão de 
educador, como questões estratégicas para o desenvolvimento da educação como um todo e da própria sociedade brasileira.

Defende, portanto, que o Estado não abdique do seu dever constitucional de manter o sistema público e gratuito de educação superior, de maneira adequada, o que implica o aporte de recursos capazes de assegurar um fluxo contínuo e suficiente para o funcionamento pleno das instituições e a implantação de uma política de longo prazo atinente à área de recursos humanos.

Entende, por fim, em nome da autonomia universitária, que o financiamento das instituições públicas deve ter por referência os planejamentos institucionais, construídos coletiva e democraticamente pelas instituições de educação superior públicas.

\section{Ampliação do acesso}

A ANPEd defende a expansão e democratização do acesso à educação superior pública, bem como uma maior e mais uniforme abrangência desse sistema no território nacional, tornando-o, desse modo, mais acessível à população brasileira. Todavia, destaca a importância de se instituir procedimentos capazes de assegurar a manutenção e ampliação dos patamares de qualidade do sistema de educação superior. Nesse sentido, posiciona-se contrariamente ao programa Universidade para Todos (medida provisória

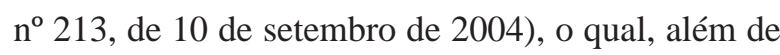
criar uma nova relação entre o setor público e privado, abrindo espaço para a emergência de uma suposta esfera pública não-estatal, não garante a reivindicada qualidade do ensino superior, além de não contemplar um crescimento articulado entre ensino, pesquisa e extensão.

Em síntese, entende-se que a necessária ampliação do acesso e dilatação da formação profissional deva conter contrapartidas imediatas e públicas relacionadas à ampliação da produção de conhecimento, tecnologia e cultura. Sem esse crescimento articulado, corre-se sério risco de reduzir as universidades e seu caráter de espaço da invenção, descoberta, pro- dução de teoria, divulgação de novos conhecimentos e encaminhamento de soluções para problemas da realidade social.

A instituição de reserva de cotas nas universidades públicas (referência ao projeto de lei n ${ }^{\circ} 3.627 / 2004$ ), seja para alunos pobres ou para auto-declarados negros e indígenas é outro motivo de preocupação da ANPEd, pois instituir as cotas desacompanhadas de um fundo de assistência estudantil, que garanta a permanência dos estudantes nos cursos, poderá transformar a democratização de acesso ao ensino superior em um discurso sedutor sem resultados reais. Além disso, entende-se que a definição das cotas não pode ferir o princípio da autonomia, situação que só não ocorrerá se couber às próprias instituições a prerrogativa de definir a melhor forma de aumentar a participação desses estudantes no ensino superior.

\section{Autonomia universitária}

A ANPEd defende que o exercício da autonomia implica a gestão democrática do projeto políticopedagógico da universidade. Defende que a universidade pública não deve se constituir como extensão de governos e sustenta esse distanciamento como condição para que a crítica da realidade social possa ser desenvolvida. Ensino, pesquisa e extensão dependem de liberdade e autonomia política. Nesse cenário, a universidade deve ter a possibilidade de definir seu próprio projeto político e ao Estado cabe acompanhar a operacionalização que a instituição faz do projeto político que ela mesma elaborou, como, por exemplo, zelando pela boa aplicação dos recursos públicos, nos termos da legislação.

Entende-se que o pressuposto básico em relação à autonomia deva residir na responsabilidade do Estado para com a viabilização desse direito, da forma mais universal e abrangente possível. Isso pressupõe, antes de qualquer coisa, o claro compromisso para com o financiamento, não só garantindo as condições de funcionamento do atual sistema público de educação superior como também viabilizando sua expansão em padrões de qualidade aceitáveis. Rejei- 
ta-se, assim, aquele tipo de articulação, já bastante criticada, entre autonomia e financiamento, sugerindo a necessidade das universidades enfrentarem a situação de crise, na medida do possível, às próprias custas ou mediante um manejo mais eficaz e otimizado dos parcos recursos de que já dispõem, ao mesmo tempo em que induz as instituições a captarem recursos por meio da venda de serviços, modificando com isso os objetivos e a identidade da instituição universitária. Nesse sentido, a ANPEd entende que a recente regulamentação das fundações (decreto $\mathrm{n}^{\circ} 5.205$ de 14 de setembro de 2004) não coibe a mercantilização que tais organismos têm provocado no cotidiano universitário.

\section{Avaliação}

Em relação à avaliação, a ANPEd alia-se aos que a vêem como um processo múltiplo que vise à construção da qualidade e da excelência não excludentes, mediante a identificação dos acertos e das dificuldades, com a finalidade de melhoria institucional e construção de instituições comprometidas com o desenvolvimento científico e social. Questiona, assim, qualquer processo avaliativo calcado em critérios de produtividade empresarial, que quantifique a atividade docente, funcione como mecanismo de distribuição de recursos para o desenvolvimento de projetos de pesquisa ou para a distribuição de incentivos salariais ao corpo docente, elegendo a "competitividade" como mola mestra do trabalho acadêmico. Entende a avaliação como um processo amplo, que deve abranger todos os segmentos e níveis institucionais e contribuir para a transformação do sistema de educação superior, o que colide frontalmente com qualquer concepção que se proponha a utilizar os resultados avaliativos para mera hierarquização de docentes, estudantes ou de instituições.

Defende, ainda, a necessidade de se instituir mecanismos que remetam à construção de uma cultura avaliativa de natureza formativa, participativa, democrática e em permanente construção capaz de firmar ao mesmo tempo, em todas as instituições, públicas ou privadas, a consciência de sua função pública e de seu compromisso público inarredável com a sociedade brasileira.

Aprovado na Assembléia Geral da $27^{\mathrm{a}}$ Reunião Anual da ANPEd, realizada em Caxambu (MG), em 23 novembro de 2004. 